\title{
Adolescent Substance Use and Comorbid Psychopathology: Emotion Regulation Deficits as a Transdiagnostic Risk Factor
}

\author{
Julia M. Shadur ${ }^{1} \cdot$ Carl W. Lejuez ${ }^{1}$
}

Published online: 7 October 2015

(C) Springer International Publishing AG 2015

\begin{abstract}
Rates of substance use and comorbid psychopathology peak during adolescence, highlighting the need to identify transdiagnostic risk processes that cut across conditions and elucidate early embedded risk factors for comorbidity across development. The current review highlights emotion regulation deficits as a core transdiagnostic risk factor underlying the development of substance use, addiction, and comorbid psychopathology in adolescence. We present the dual systems model of neurological development to highlight adolescence as a critical period of increased risk for emotion regulation difficulties, corresponding risk behaviors, and psychopathology. We describe malfunction in the neurobiological regulation system underlying the relationship between emotion regulation and risk for addiction and comorbidity. We pull from two established developmental theories including both the externalizing pathway and the internalizing pathway to substance use disorders, which together highlight how early embedded risk in the form of emotion regulation deficits can explain mechanisms underlying the development of addiction and comorbid psychiatric disorders.
\end{abstract}

Keywords Emotion regulation - Transdiagnostic $\cdot$ Substance use $\cdot$ Comorbidity $\cdot$ Psychopathology $\cdot$ Adolescence

This article is part of the Topical Collection on Transgenerational Considerations in Addictions

Julia M. Shadur

jshadur@umd.edu

Carl W. Lejuez

clejuez@umd.edu

1 Department of Psychology, Center for Addictions, Personality, and Emotion Research, University of Maryland at College Park, 2103 Cole Field House, College Park, MD 20742, USA

\section{Introduction}

Adolescence marks a period of notably increased risk for substance use and alcohol and substance use disorders (AUDs/SUDs), as well as comorbid psychopathology [1]. Substance use escalates significantly through high school where $68 \%$ of 12 th graders have tried alcohol, $46 \%$ marijuana, and $25 \%$ any illicit drug other than marijuana [2], with overall rates of substance use peaking between the ages of 16 and $25[3 \cdot \bullet]$. Approximately $2.8 \%$ of youths aged $12-17$ in the USA meet criteria for an AUD and 3.5\% meet criteria for an SUD, with a combined $5.2 \%$ meeting criteria for either an AUD and/or an SUD [4]. Rates of adolescent internalizing disorders (e.g., depressive disorders $8.2 \%$ [5]; anxiety disorders $12.7 \%$ [6]) and externalizing disorders (e.g., disruptive behavior disorders $22.9 \%$ and attention deficit hyperactivity disorder $17.5 \%$ [6]) are even higher. Further, up to $40 \%$ of youths with an AUD/SUD also meet the criteria for at least one other comorbid psychiatric disorder [7], and $25 \%$ of adolescents aged 11-17 who are admitted into inpatient psychiatric hospitals meet the criteria for comorbid mental health and substance use disorders [8]. Comorbidity of AUDs/SUDs with other psychiatric conditions is associated with increased disorder severity and poorer outcomes among youths [7, 9]. Peak rates of these disorders emerge in early adolescence and continue through young adulthood, pinpointing adolescence as a particularly vulnerable and sensitive period for the development of psychopathology.

Prevention efforts are targeted at early risk factors that explain the development of comorbid psychopathology, with a narrowing focus on transdiagnostic factors that cut across conditions and thus further exacerbate psychopathology risk $[10,11 \bullet \cdot, 12 \bullet, 13]$. The Research Domain Criteria (RDoC)a recent initiative put forth by the National Institute of Mental Health-encourages research focused on unmasking 
biological and psychosocial mechanisms and underpinnings that characterize multiple psychiatric disorders $[10,14]$. In line with the $\mathrm{RDoC}$ framework, the goal of this review is to integrate recent findings on common underlying risk mechanisms that transcend across comorbid psychological disorders. We focus on emotion regulation deficits as a core transdiagnostic risk factor underlying the development of substance use, addiction, and comorbid psychopathology in adolescence. Indeed, disordered and dysregulated mood defines many forms of psychopathology, and difficulty with emotion regulation has been described as a core deficit that emerges across psychiatric disorders and manifests as dysregulation across multiple levels of analysis - biology, physiology, and behavior [15]. Consistent with the theme of this special issue, we emphasize examples of biologically-based indices of emotion regulation deficits, but include supporting data from behavioral and psychosocial-based research as well.

\section{Emotion Regulation: Definition}

Current definitions of "emotion regulation" vary quite dramatically both within and across disciplines (a thorough review of the construct of emotion regulation is beyond the scope of this report, but see $[15-17,18 \bullet, 19]$ for recent reviews). For parsimony, our definition of emotion regulation for the current review includes the following: efforts, strategies, and responses, whether conscious or not, involved in modifying or maintaining an emotional state and associated behaviors [e.g., 15, 19-21]. This definition allows for inclusion of multiple dimensions of emotionally-salient processes and regulation of these processes, including but not limited to: emotional reactivity, arousal, sympathetic and parasympathetic activity, impulsivity, effortful control, behavioral and emotional inhibition, emotional awareness, and features of temperament [e.g., 16, 17, 18 , 22]. We employ this more versatile definition of emotion regulation in order to maximize inclusion of findings from research which spans across various emotionally-salient domains as they relate to substance use and comorbid psychopathology.

\section{Emotion Regulation Development}

Overview Development of self-control and adaptive emotion regulation strategies is an ongoing process that progresses rapidly through the preschool years [23] and continues to develop and emerge through adolescence [24] and into emerging adulthood [18•] (see [15] for a review of emotion regulation development). Emotion regulation is a relatively stable construct with known behavioral and neurobiological correlates that reliably predict individual differences in self-regulation and impulse control across the lifetime [e.g., 25].
Adolescence as a Critical Developmental Period Adolescents are particularly vulnerable to emotion regulation difficulties. Emotion regulation deficits are one of the many challenges youths face that contributes to the steep escalation in rates of comorbid psychiatric conditions observed throughout adolescence, including increased internalizing, externalizing, and substance use disorders $[10,26]$. In addition to the increased stress related to goals of identity development, the onset of puberty, and increasing peer influences [26, 27], adolescents are more vulnerable to elevated emotionality and increased negative affect, and experience more labile and dysregulated mood compared to adults $[21,28,29 \bullet \cdot, 30]$. Youths are also more likely to have these volatile and dysregulated emotional experiences impact their behavior and decision making [30]. Indeed, greater intra-individual fluctuations in negative affect, conceptualized as dysregulated mood, predict increased risk for adolescent substance use at the daily level [31] and also predict growth in drug use over time [32], as well as more significant symptoms of impairment [33]. Thus, adolescence is a critical developmental window in which emotional dysregulation contributes to increased risk for psychopathology and addiction.

Neurobiology underlying Adolescent Vulnerability to Emotion Regulation Deficits Much of the work examining adolescents' experiences of dysregulated and volatile mood highlights neurobiological changes and wiring in the adolescent brain related to the limbic-striatal system and the prefrontal cortex (PFC) and related circuitry. We focus on how this particular neurological mechanism underlying emotion regulation develops and changes during adolescence in a way that helps explain the increased risk for comorbid psychopathology during this critical developmental window. Specifically, established findings show that adolescents are at a developmental stage in which the limbic-striatal system (responsible for emotional drive, emotional response, arousal, novelty- and sensation-seeking, and reward sensitivity) is more quickly and fully developed than the PFC and related circuitry, which is not fully developed until adulthood (responsible for selfregulation, emotional control, impulse and cognitive control, planning, decision making, and executive functioning) (see $[3 \bullet \bullet, 29 \bullet \bullet, 34-36,37 \bullet \cdot, 38]$ for reviews). ${ }^{1}$

This pattern of differential neurological development has been referred to as the dual systems model or the maturational imbalance theory [e.g., 36, 43••]; however, there are competing views of this model (see $[43 \bullet \bullet, 44,45]$ for a discussion of

\footnotetext{
${ }^{1}$ An extensive review of the unique and interactive functions across neurobiological regions is beyond the scope of this brief report, and thus we highlight several specific and robust examples in which emotion regulation difficulties manifest as neurobiological differences and help explain risk for comorbid disorders among youths. We refer the reader elsewhere for more extensive and detailed accounts of neural circuits and functions related to psychopathology [e.g., 38, 39••, 40-42].
} 
these issues and related controversies). The resulting developmentally normative mismatch between increased emotional volatility combined with an underdeveloped regulation system means that for youths particularly at risk (e.g., children of substance-dependent parents [46], those with environmental or genetic risk [29••], or psychosocial stress [38]), difficulty with emotion regulation is an identifiable, transdiagnostic, early embedded risk for psychopathology in adolescence-including disorders of addiction, as well as internalizing and externalizing problems $[3 \bullet \bullet, 11 \bullet \bullet, 15,17,19,47-49,50 \bullet, 51 \bullet \bullet, 52,53 \bullet, ~ 54-56]$.

Empirical work consistently shows differences in neurological activity during adolescence with respect to the processing of emotional information and emotion regulation. Compared to both children and adults, neurological circuits responsible for emotionally-salient cue responses are more active among adolescents, including an elevated amygdala response to threat $[29 \cdot \bullet, 57]$ and elevated ventral striatum activity in response to rewards [3••]. Adolescents with a positive family history of SUD (i.e., at least one parent with an SUD) also show greater amygdala activation in response to emotional stimuli [46]. This pattern of activity in the amygdala is indicative of a hyperactive emotional response system and also indicates poorer PFC regulation [46]. These observed differences in neurological activity, consistent with the dual systems model, contribute to increased emotional volatility and difficulty with emotion regulation that increases during adolescence, which ultimately manifests as increased risk for SUDs and comorbid psychopathology (e.g., [29••, 36]).

\section{Neurobiology of Emotion Regulation and Parallel Behav-} ioral Correlates The observed imbalance in development between the neurological "gas" and "brake" systems [37••] during adolescence generally maps onto behavioral and self-report indices of these regulatory processes as well, with reward sensitivity, sensation-seeking, preference for short-term rather than long-term rewards, and risk-taking behavior also peaking during adolescence, whereas inhibitory behavior and impulse control follows a linear trajectory over time, peaking later in development (see [35, 36, 43••] for reviews). ${ }^{2}$ Behavioral indices

\footnotetext{
${ }^{2}$ However, we note that patterns of developmental trajectories of risky decision making may depend on the methodology employed, with a recent meta-analysis [44] showing that when completing behavioral labbased tasks, adolescents take more risks than adults (as expected), but are comparable, or in some cases, less risky than children (contrary to the expected curvilinear trajectory over time), whereas real-world behavioral measures show that adolescents take more risks than both children and adults. Determining why we observe curvilinear versus linear trajectories in risky decision making across development as a function of methodology is an area for future research. In either case, however, regulation and self-control are not fully developed until adulthood, and adolescence - as compared to childhood - is a period of heightened risk due to increased opportunities and exposure to contexts of drug use and other risky behaviors (e.g., deviant peer networks [58]).
}

of disinhibition and regulation in early childhood also map onto the underlying neurobiological regulation mechanisms and correlates over time. In a classic delay of gratification task ("the marshmallow test" [37••]), young children (age 4) were presented with a choice: one marshmallow now, or two after a delay. Individuals who were better able to delay as a child showed greater PFC activity in adolescence and adulthood when presented with a rewarding, tempting stimulus, whereas those who struggled with the delay task in childhood showed greater activity in the ventral striatum and less effective PFC recruitment when in the face of positive reward cues $[25,37 \cdot \bullet]$. Moreover, robust findings showed that children who were able to wait for two marshmallows showed better self-control and focus in adolescence, and even into adulthood were more likely to reach their long-term goals and were at significantly decreased risk for SUDs [37•0]. This pattern of findings reflects heterotypic continuity [59] such that the same core underlying deficit (in this case, emotion regulation) is reflected over time but may manifest in different ways across development. This work underscores emotional and behavioral regulation difficulties in early childhood as an embedded risk for later risk-taking and impulsive behavior, setting the stage for substance use disorders and comorbid psychopathology across the lifetime [e.g., 36].

\section{Emotion Regulation Deficits and Risk for Psychopathology}

Deficits in emotion regulation in many cases is the defining feature of psychiatric disorder, and emotion regulation deficits predict multiple indices of child and adolescent adjustment throughout development, including internalizing and externalizing symptoms as well substance use and risk for addiction [e.g., 11••, 15, 17, 26, 47, 48, 52, 53••, 60]. Further, emotion dysregulation uniquely predicts psychopathology symptoms across a range of disorders, above and beyond the mere experience of negative affect alone [61]. In sum, there is a robust association between emotion regulation difficulties and the development of psychopathology, particularly during the high-risk period of adolescence.

Efforts to explain this link between emotion regulation and comorbid psychopathology in adolescence point to neurobiology and neural circuitry. The neurobiological mechanism underlying emotion regulation deficits (simply put: a more active emotional response system and less effective regulation of the emotional response) is both (1) the normative developmental imbalance during adolescence (reviewed above), and (2) a parallel process that underlies and further exacerbates risk for addiction and comorbid psychopathology more generally. Indeed, less effective regulation by the PFC in the face of hyperactive subcortical regions is part of what explains the notable links between stress, emotion regulation difficulties, 
risk for addiction, and comorbid disorders [e.g., 38, 40], and similar underlying neurobiological systems and circuits are implicated in risk for affective disorders, self-control, self-regulation, and risk for addiction [e.g., 38, 50•, 62, 63]. The neurobiological processes underlying emotion regulation deficits can manifest across development in the form of internalizing, externalizing, and/or SUDs, depending on the manner in which the response and regulation system becomes dysfunctional [54]. In other words, emotion dysregulation as a core deficit serves as an embedded risk factor that can lead to multiple, different outcomes (i.e., "multifinality" [13]).

\section{Emotion Regulation and Substance Use Risk}

Overview Emotion regulation deficits have been established as robust predictors of substance use risk [52, 53••, 64-69]. Cognitive neuroscience studies have also shown that individuals with SUDs exhibit less effective emotion regulation [70]. Furthermore, individuals with SUDs and comorbid psychopathology show even greater deficits in emotion regulation [71], and substance use risk is greater among those who experience distress and related psychiatric affective disorders [28]. At the point of disorder, less effective emotion regulation and poorer self-control also predict less successful substance use treatment outcomes, including poorer treatment persistence and increased rates of relapse [67, 72].

Dysregulated and negative mood play a key role in the development of addictive disorders. Negative reinforcement models of substance use posit that the use of drugs serves to regulate emotion by removing the stimulus responsible for the experience of negative affect (and symptoms of withdrawal with increasingly severe SUDs), thus further reinforcing subsequent use of drugs over time [73-75]. ${ }^{3}$ Substance use may thus serve as a means of coping with the increased negative affect and dysregulated mood related specifically to internalizing and externalizing disorders [e.g., 78]. It is also important to highlight that emotion regulation difficulties play a role as both a cause and a consequence of drug use, with bidirectional effects showing that poorer emotion regulation predicts increased drug use, but increased drug use also predicts poorer emotion regulation [for reviews, see $28,38,50 \bullet 53 \bullet \bullet$.

\section{Neurobiology of Emotion Regulation Deficits underlying} Risk for Addiction The dual systems model highlights how emotion regulation difficulties, reward-seeking, sensationseeking, and impulsivity increase during adolescence, placing youths at further risk for engaging in drug use and other risk

\footnotetext{
${ }^{3}$ Although beyond the scope of this review, we refer the reader elsewhere for a more detailed review of the negative-affect-based processes underlying substance use risk, including the importance of discerning withinperson versus between-person mechanisms linking negative affect to drug use (see $[28,76,77 \cdot]$ for a more detailed discussion of these issues).
}

behaviors [e.g., 43••, 79]. The underlying mechanism reflects a hyperactive subcortical system and an underdeveloped PFC. With regard to the onset and maintenance of SUDs, recent work builds upon the dual systems model and focuses on the uniquely important role of the PFC as a key center of emotional and behavioral regulation $[40,53 \cdot \bullet]$. The PFC is the primary source of disruption in emotion regulation with respect to the development of SUDs, with reduced PFC volume and thickness as well as lower activation in areas responsible for emotion regulation and executive functioning among individuals with SUDs [53・•]. This model describes how drug craving leads to increased activation in subcortical regions (specifically the ventral striatum and amygdala), and opportunities for regulation of the experience of craving and associated negative affect can come either from the PFC or from the direct effects of drug use. In cases where the PFC is less effectively able to regulate, as is the case for those with SUDs, drug use may be the selected way to cope with and regulate distress. This then begins a problematic negative cycle in which the use of drugs further compromises the regulation abilities of the PFC, leading to further emotion regulation deficits and risk for other forms of comorbid psychopathology $[53 \cdot \bullet]$.

Further, substance abusers are more likely to have greater sensitization and dysfunctional limbic system responses to negative affect and also exhibit greater connectivity between the limbic and PFC regions during emotional processing, but lower levels of connectivity during cognitive reappraisal and regulation tasks, indicative of poorer regulation of negative emotional experiences and less effective cognitive control [70]. Indeed, elevated limbic system response and activity in the amygdala and ventral striatum, combined with decreased regulatory response of the PFC, define the emotion regulation difficulties [e.g., 39••] that provoke substance use in the first place $[53 \bullet \bullet, 65]$ and also increase the risk for other psychiatric disorders consistent with deficits in emotion regulation, including internalizing and externalizing disorders [39••].

\section{Developmental Pathways to Addiction and Comorbid Psychopathology_Putting it All Together}

Deficits in emotion regulation prescribe the onset of risk in two prominent developmental pathways leading to SUDs and comorbid psychopathology, including the externalizing pathway $[80,81]$ and the internalizing pathway $[82,83 \cdot 0]$. Although core to both pathways, the manifestation of such emotion regulation deficits may be different (e.g., more inhibited behavior for those who develop comorbid internalizing symptoms and SUDs [82]). However, of note is the high comorbidity between internalizing and externalizing disorders, and thus these risk trajectories are not considered mutually exclusive 
pathways (see [83••] for a more thorough discussion of these issues).

\section{The Externalizing Pathway to Substance Use Disorders} The externalizing pathway to SUDs is a well-known developmental theory which posits that behavioral disinhibition, undercontrol, and poor regulation in early childhood underlie risk across development, manifesting as comorbid externalizing and SUDs over time [80, 81]. In this developmental trajectory, childhood impulsivity and behavioral disinhibition predict disruptive behavior disorders and increased externalizing symptoms in adolescence, which is further exacerbated by environmental risk, ultimately leading to comorbid externalizing and SUDs into adulthood [80].

The externalizing pathway highlights the underlying neurological systems of increased reward sensitivity and reactivity combined with decreased effortful control and regulation that are imbalanced and competing during adolescence (i.e., dual systems model), which further contributes to adolescence being a high-risk period for the onset of substance use and comorbid behavior problems [80, 81]. Indeed, ventral striatum hyperactivity in response to positive reward cues is related to greater behavioral disinhibition and risky decision making, as well as delinquent and impulsive behaviors [39••]. This hyperactive affective response to reward cues combined with poor regulation and compromised executive functioning is associated with risk for comorbid SUDs and externalizing symptoms, including conduct disorder [e.g., 26]. Findings show that PFC functioning is impaired among youths with disruptive behavior disorders and SUDs, particularly leading to impairment of decision making in the context of tempting rewards [84]. Compared to healthy controls, youths with externalizing disorders also exhibit smaller PFC and amygdala volumes, indicating more disinhibited behavior and poorer regulation [84-86].

Although patterns of increased reward sensitivity and poor regulation of affective responses to rewards are evidenced in many studies, there have been mixed findings among youths with disruptive behavior disorders, with results showing either more or less reactive amygdala responses among these youths [84]. Part of what might explain these differences comes from work suggesting that youths with disruptive behavior disorders may actually show lower neural sensitivity to rewards, leading them to engage in more sensation-seeking and rewardseeking behavior to compensate for this lack of sensitivity (see [84] for a review). Indeed, compared to a community control group of boys, adolescent boys diagnosed with comorbid conduct and substance use disorders exhibited hypoactivation in a number of brain regions comprising the limbic-striatal system (including the amygdala) and PFC regions during a risky decision making task with the possibility of gaining rewards [87]. The boys with comorbid psychopathology also showed hypoactivation in response to rewards, consistent with reward insensitivity. Smaller amygdala volumes have been found among youths with disruptive behavior disorders which could also contribute to findings showing diminished reward sensitivity among these youths [84-86]. Differences in reactivity across these brain regions may depend on several factors, including the particular neurological system and circuit of study, the specific lab-based task, and the specific externalizing disorder, a clear direction for future research efforts.

The Internalizing Pathway to Substance Use Disorders Emotional lability and affect regulation also serve as a common underlying risk factor for comorbid internalizing and SUDs [40, 77•]. However, in contrast with the externalizing pathway which focuses on behavioral disinhibition, the internalizing pathway to comorbid affective and SUDs posits that behaviorally inhibited temperament and poor emotion regulation early in development predict increased internalizing symptoms and compromised emotion regulation throughout adolescence, ultimately leading to comorbid negative affect and substance use disorders $[82,83 \bullet \bullet]$.

A behaviorally inhibited temperamental style can be conceptualized as a form of emotional dysregulation. Behavioral inhibition is characterized by a heightened startle and stress response, elevated response to novelty, negative emotionality, physiological dysregulation, attentional bias toward threat, misinterpretation of neutral cues as threatening, social reticence, and social skill deficits [e.g., 88, 89]. The biological and behavioral correlates of behavioral inhibition are relatively stable and predict increased risk for internalizing disorders [90] and substance use over time [89]. Furthermore, behavioral inhibition interacts with risk-taking propensity, such that increased behavioral inhibition is associated with substancerelated problems specifically among youths with high levels of risk-taking propensity [89].

Behavioral inhibition is also implicated in the underlying mechanisms linking emotion regulation to comorbid psychopathology via social skill impairment in childhood. For children with highly inhibited temperamental styles, behavioral inhibition at ages $2-3$ predicts more compromised emotion regulation abilities at age 5 , which subsequently predicts more impaired social skills at age 7 [91]. Early social skill deficits are implicated as a continued risk factor propelling youths along the internalizing pathway to comorbid affective disorders and SUDs [82], and thus behavioral inhibition and corresponding difficulty with emotion regulation deficits in childhood serve as an early embedded risk underlying the internalizing pathway.

The core neurobiological regulation system we have highlighted throughout this review is implicated in the risk for internalizing and SUDs as well, and maps onto the temperamental features of behavioral inhibition over time [92]. Highly inhibited children at age 5 show greater right 
orbitofrontal cortex and amygdala volume at age 15, consistent with models of over-regulation and inhibition [85]. Robust findings also show that behaviorally inhibited children and those with anxiety disorders show a hyperactive amygdala response to threat $[90,93]$, and adolescents with internalizing disorders generally show greater activity in both the amygdala and PFC regions in response to emotionally-salient stimuli [94]. Individuals with internalizing disorders also show more limited connectivity between the amygdala and regions of the $\mathrm{PFC}$, contributing to less effective regulation of the fear response [29••, 39••, 90]. Collectively, this is indicative of a threat-response system that is overly sensitized, with greater amygdala activation combined with more compromised PFC suppression and down-regulation of the emotional threat response [36, 38, 39••, 40, 95].

The link between this heightened emotional response to threat and poor emotion regulation further increases risk for comorbid internalizing and substance use disorders. In contexts of heightened emotional stress and dysregulated states, individuals with comorbid internalizing and substance use disorders may be more likely drawn to drugs as a means to cope, which not only limits learning of effective emotion regulation and coping strategies, but also further reinforces addictive behaviors. Support for this has been found among individuals diagnosed with comorbid PTSD and cocaine dependence who demonstrate an attentional bias toward drug cues specifically when prompted with an emotionally threatening stimulus involving a personal trauma script exposure [96]. Collectively, this pattern of results maps on to the risk trajectory outlined in the internalizing pathway [82]. Indeed, for youths with a history of early behavioral inhibition, emotion regulation difficulties, social skill deficits, and poor coping strategies, drug use may serve as a source of regulation and means to cope particularly in contexts of elevated threat and stress, ultimately leading to comorbid affective and substance use disorders later in development. More advanced mapping of the neurobiological risk factors underlying this developmental pathway is an area for future research efforts.

\section{Conclusions and Future Directions}

Although the scope of this report allows only a targeted review of the link between emotion regulation deficits and risk for comorbid psychopathology in adolescence, the extant literature indicates that emotion regulation is indeed a core transdiagnostic risk factor that represents early embedded risk for the development of substance use, addiction, and comorbid psychopathology. Deficits in emotion regulation emerge during adolescence in part due to the dual systems model of imbalanced neurological development between the response and regulation systems, a risk process which is then exacerbated in contexts where the same response and regulation system malfunctions in various ways that can lead to multiple forms of psychopathology. Collectively, this area of research indicates that emotion regulation is a key treatment target for intervention and prevention efforts focused on minimizing psychopathology risk. In addition to supporting individual emotion regulation development and strategies, this work also suggests that minimizing contextual stressors and environmental risk will be critical as well-stressors that we know further compromise emotion regulation abilities (e.g., see [97] for a review of the effects of environmental stress on the response and regulatory systems and subsequent risk for psychopathology).

We note that this review was intentionally limited in scope, leaving many other considerations that must be addressed in the discussion of a topic as large as the risk and development of comorbid psychopathology. Additional factors that must be considered include, but are not limited to, genetic risk, environmental risk, contextual stressors and trauma, parental psychopathology and substance use, and peer influences, with all of these factors interacting with emotion regulation to predict outcomes. Consistent with the frameworks of developmental psychopathology and developmental science [16, 98, 99], we recognize that these complex developmental risk mechanisms must consider transactional processes across multiple levels of analysis (e.g., genetic, neurobiological, behavioral, dyadic, environmental), over time, and across development [12••]. This leaves significant work for future research efforts to continue identifying transdiagnostic risk processes, such as emotion regulation, and examining how these transdiagnostic processes interact with each other over time. These efforts will require a focus on developmental pathways themselves as the outcomes of interest, moving away from a simpler variable-focused approach. Indeed, the internalizing and externalizing pathways reviewed here highlight the developmental processes and risk trajectories as the specific focus of study [83••]. A clear next step for future research on the topic of addiction and comorbid psychopathology will be to examine how these early developmental risk processes relate to the intergenerational transmission of emotion regulation deficits, addiction, and psychopathology risk.

\section{Compliance with Ethics Guidelines}

Conflict of Interest Julia M. Shadur and Carl W. Lejuez declare that they have no conflict of interest.

Human and Animal Rights and Informed Consent With regard to the authors' research cited in this paper, all procedures were followed in accordance with the ethical standards of the institutional and/or national research committee on human subjects research and with the Declaration 
of Helsinki and its later amendments. This article does not contain any studies with animal subjects performed by any of the authors.

\section{References}

Papers of particular interest, published recently, have been highlighted as:

- Of importance

- Of major importance

1. Roten AT, Gray KM. Adolescent substance use disorders: epidemiology, neurobiology, and screening. In: Galanter M, Kleber HD, Brady KTM, editors. The American Psychiatric Publishing textbook of substance abuse treatment. 5th ed. Arlington: American Psychiatric Publishing, Inc.; 2015. p. 635-40.

2. Johnston LD, O'Malley PM, Miech RA, Bachman JG, Schulenberg JE. Monitoring the future national results on drug use: 1975-2013: overview, key findings on adolescent drug use. Ann Arbor: Institute for Social Research, The University of Michigan; 2014.

3.• Caudle K, Casey BJ. Brain development and the risk for substance abuse. In: Charney DS et al., editors. Neurobiology of mental illness. 4th ed. New York: Oxford University Press; 2013. p. 706-15. doi:10.1093/med/9780199934959.003.0053. This chapter describes brain development and changes in brain circuitry during adolescence and how such changes can underlie risk for the development of substance use disorders. The authors highlight how such mechanisms can help identify both who is at greatest risk and when during development the greatest risk exists.

4. Abuse S, Administration MHS. Results from the 2013 National Survey on Drug Use and Health: summary of national findings, NSDUH series H-48, HHS publication no. (SMA) 14-4863. Rockville: Substance Abuse and Mental Health Services Administration; 2014.

5. Blanco C, Wall MM, He J, Krueger RF, Olfson M, Jin CJ, et al. The space of common psychiatric disorders in adolescents: comorbidity structure and individual latent liabilities. J Am Acad Child Adolesc Psychiatry. 2015;54(1):45-52. doi:10.1016/j.jaac.2014.10.007.

6. Merikangas KR, Calkins ME, Burstein M, He J, Chiavacci R, Lateef $\mathrm{T}$, et al. Comorbidity of physical and mental disorders in the neurodevelopmental genomics cohort study. Pediatrics. 2015;135(4):e927-38. doi:10.1542/peds.2014-1444.

7. Zorick T (2013). Psychiatric comorbidities in adolescent substance use disorders. In R. Rosner (Ed.), Clinical Handbook of Adolescent Addiction. (pp. 88-98). Wiley-Blackwell.

8. Hollen V, Ortiz G. Mental health and substance use comorbidity among adolescents in psychiatric inpatient hospitals: prevalence and covariates. J Child Adolesc Subst Abus. 2015;24(2):102-12. doi:10.1080/1067828X.2013.768575.

9. van West D, Vermeiren R. Dual disorders in adolescent populations. In: Dom G, Moggi F, editors. Co-occurring addictive and psychiatric disorders: a practice-based handbook from a European perspective. New York: Springer-Verlag Publishing; 2015. p. 335-47. doi: 10.1007/978-3-642-45375-5 22.

10. Casey BJ, Oliveri ME, Insel T. A neurodevelopmental perspective on the research domain criteria (RDoC) framework. Biol Psychiatry. 2014;76:350-3. doi:10.1016/j.biopsych.2014.01.006.

11.• Ehring T. Editorial for special issue emotion regulation and psychopathology. J Exp Psychopathol. 2013;4(5):448-50. This introductory editorial for the special issue on emotion regulation and psychopathology provides a succinct overview of the importance of considering emotion regulation deficits as a key transdiagnostic risk factor underlying various forms of psychopathology.

12.• Hussong AM, Burns AR, Solis JM, Rothenberg WA. Future directions in the developmental science of addictions. J Clin Child Adolesc Psychol. 2013;42(6):863-73. doi:10.1080/15374416. 2013.838772. This paper provides an important discussion around considering the developmental context and employing the developmental science framework to help researchers examine the mechanisms by which substance use disorders develop over time and across development. The authors also highlight the importance of identifying core underlying common deficits across disorders as a way to elucidate early risk for the development of addiction.

13. Nolen-Hoeksema S, Watkins ER. A heuristic for developing transdiagnostic models of psychopathology: explaining multifinality and divergent trajectories. Perspect Psychol Sci. 2011;6(6):589-609. doi:10.1177/1745691611419672.

14. Insel TR. The NIMH research domain criteria (RDoC) project: precision medicine for psychiatry. Am J Psychiatr. 2014;171(4): 395-7.

15. Thompson RA, Goodman M. Development of emotion regulation: more than meets the eye. In: Kring AM, Sloan DM, editors. Emotion regulation and psychopathology: a transdiagnostic approach to etiology and treatment. New York: Guilford Press; 2010. p. 38-58.

16. Adrian M, Zeman J, Veits G. Methodological implications of the affect revolution: a 35-year review of emotion regulation assessment in children. J Exp Child Psychol. 2011;110(2):171-97. doi: 10.1016/j.jecp.2011.03.009.

17. Berking M, Wupperman P. Emotion regulation and mental health: recent findings, current challenges, and future directions. Curr Opin Psychiatry. 2012;25(2):128-34. doi:10.1097/YCO. 0b013e3283503669.

18. Bridgett DJ, Burt NM, Edwards ES, Deater-Deckard K. Intergenerational transmission of self-regulation: a multidisciplinary review and integrative conceptual framework. Psychol Bull. 2015;141(3):602-54. doi:10.1037/a0038662. This review presents a culmination of research highlighting the intergenerational transmission of emotion regulation and describes mechanisms underlying this transmission from parents to children over time. The authors present their "selfregulation intergenerational transmission model" as a framework for understanding the multiple interacting processes underlying such mechanisms of transmission.

19. Gratz KL, Tull MT. Emotion regulation as a mechanism of change in acceptance- and mindfulness-based treatments. In: Baer RA, editor. Assessing mindfulness and acceptance processes in clients: illuminating the theory and practice of change. Oakland: Context Press/New Harbinger Publications; 2010. p. 107-33.

20. Calkins SD, Leerkes EM. Early attachment processes and the development of emotional self-regulation. In: Vohs KD, Baumeister RF, editors. Handbook of self-regulation: research, theory, and applications. 2nd ed. New York: Guilford Press; 2011. p. 355-73.

21. Riediger M, Klipker K. Emotion regulation in adolescence. In: Gross J, editor. Handbook of emotion regulation. 2nd ed. New York: The Guilford Press; 2014. p. 187-202.

22. Eisenberg N, Smith CL, Spinrad TL. Effortful control: relations with emotion regulation, adjustment, and socialization in childhood. In: Vohs KD, Baumeister RF, editors. Handbook of self-regulation: research, theory, and applications. 2nd ed. New York: Guilford Press; 2011. p. 263-83.

23. Blair C, Diamond A. Biological processes in prevention and intervention: the promotion of self-regulation as a means of preventing school failure. Dev Psychopathol. 2008;20(3):899-911. doi:10. 1017/S0954579408000436. 
24. Fjell AM, Walhovd KB, Brown TT, Kuperman JM, Chung Y, Hagler DJJ, et al. Multimodal imaging of the self-regulating developing brain. PNAS Proc Ntnl Acad Sci USA. 2012;109(48): 19620-5. doi:10.1073/pnas.1208243109.

25. Casey BJ, Somerville LH, Gotlib IH, Ayduk O, Franklin NT, Askren MK, et al. Behavioral and neural correlates of delay of gratification 40 years later. PNAS Proc Ntnl Acad Sci USA. 2011;108(36):14998-5003. doi:10.1073/pnas.1108561108.

26. Brown SA, McGue M, Maggs J, Schulenberg J, Hingson R, Swartzwelder S, et al. Underage alcohol use: summary of developmental processes and mechanisms: ages 16-20. Alcohol Res Health. 2009;32(1):41-52.

27. Brown SA, McGue M, Maggs J, Schulenberg J, Hingson R, Swartzwelder S, et al. A developmental perspective on alcohol and youths 16 to 20 years of age. Pediatrics. 2008;121:S290-310. doi:10.1542/peds.2007-2243D.

28. Kassel JD, Hussong AM, Wardle MC, Veilleux JC, Heinz A, Greenstein JE, et al. Affective influences in drug use etiology. In: Scheier LM, editor. Handbook of drug use etiology: theory, methods, and empirical findings. Washington, DC: American Psychological Association; 2010. p. 183-205.

29.• Powers A, Casey BJ. The adolescent brain and the emergence and peak of psychopathology. J Infant, Child Adolesc Psychother. 2015;14(1):3-15. doi:10.1080/15289168.2015.1004889. This review highlights the neurobiological challenges during the critical period of adolescence, as well as additional contexts of risk (environmental, genetic) that further exacerbate the neurobiological risk processes underlying the development of poor emotion regulation and risk for anxiety disorders among youth.

30. Spear LP. Rewards, aversions, and affect in adolescence: emerging convergences across laboratory animal and human data. Dev Cogn Neurosci. 2011;1(4):390-403. doi:10.1016/j.den.2011.08.001.

31. Shadur JM, Hussong AM, Haroon M. Negative affect variability and adolescent self-medication: the role of the peer context. Drug Alcohol Rev. 2015. doi:10.1111/dar.12260.

32. Weinstein SM, Mermelstein R, Shiffman S, Flay B. Mood variability and cigarette smoking escalation among adolescents. Psychol Addict Behav. 2008;22(4):504-13. doi:10.1037/0893-164X.22.4. 504.

33. Simons JS, Wills TA, Neal DJ. The many faces of affect: a multilevel model of drinking frequency/quantity and alcohol dependence symptoms among young adults. J Abnorm Psychol. 2014;123(3): 676-94. doi:10.1037/a0036926.

34. Casey BJ. The teenage brain: an overview. Curr Dir Psychol Sci. 2013;22(2):80-1. doi:10.1177/0963721413486971.

35. Casey BJ, Jones RM. Neurobiology of the adolescent brain and behavior: implications for substance use disorders. J Am Acad Child Adolesc Psychiatry. 2010;49(12):1189-201.

36. Casey BJ, Jones RM, Somerville LH. Braking and accelerating of the adolescent brain. J Res Adolesc. 2011;21(1):21-33. doi:10. 1111/j.1532-7795.2010.00712.x.

37.• Mischel W. The marshmallow test: mastering self-control. New York: Little, Brown and $\mathrm{Co} ; 2014$. This book provides a detailed summary of decades of research examining early indices of emotion regulation and self-control and how early embedded risk in the form of failure to delay gratification emerges over time and across development in the form of disordered behavior and risk for psychopathology.

38. Seo D, Sinha R (2011). Neural mechanisms of stress and addiction. In B. Adinoff \& E.A. Stein (Eds.), Neuroimaging in addiction, (pp. 211-233). Wiley-Blackwell. doi:10.1002/9781119998938.ch9

39.• Hariri AR. Looking inside the disordered brain: an introduction to the functional neuroanatomy of psychopathology. Sunderland: Sinauer Associates, Inc; 2015. This book provides a detailed overview of normative neurological circuitry and development as well as describing the neuroanatomy and neurological mechanisms and processes that malfunction in the context of specific psychiatric disorders.

40. Johnstone $\mathrm{T}$, Walter $\mathrm{H}$. The neural basis of emotion dysregulation. In: Gross J, editor. Handbook of emotion regulation. 2nd ed. New York: The Guilford Press; 2014. p. 58-75.

41. Ochsner KN, Gross JJ. The neural bases of emotion and emotion regulation: a valuation perspective. In: Gross J, editor. Handbook of emotion regulation. 2nd ed. New York: The Guilford Press; 2014. p. 23-42.

42. Schumann G, Binder EB, Holte A, de Kloet ER, Oedegaard KJ, Robbins TW, et al. Stratified medicine for mental disorders. Eur Neuropsychopharmacol. 2014;24(1):5-50. doi:10.1016/j. euroneuro.2013.09.010

43.• Strang NM, Chein JM, Steinberg L. The value of the dual systems model of adolescent risk-taking. Front Hum Neurosci. 2013;7:1-4. doi:10.3389/fnhum.2013.00223. This paper provides an important review of the dual systems model of neurological development during the critical period of adolescence and how this pattern of imbalance relates to adolescent risktaking. The authors present and describe current controversies regarding the dual systems model and articulate the arguments for and against its validity.

44. Defoe IN, Dubas JS, Figner B, van Aken MAG. A meta-analysis on age differences in risky decision making: adolescents versus children and adults. Psychol Bull. 2015;141(1):48-84. doi:10.1037/ a0038088.

45. Pfeifer JH, Allen NB. Arrested development? Reconsidering dualsystems models of brain function in adolescence and disorders. Trends Cogn Sci. 2012;16(6):322-9. doi:10.1016/j.tics.2012.04. 011.

46. Lindsay DL, Pajtek S, Tarter RE, Long EC, Clark DB. Amygdala activation and emotional processing in adolescents at risk for substance use disorders. J Child Adolesc Subst Abus. 2014;23(3):200 4. doi:10.1080/1067828X.2014.889515.

47. Beauchaine TP. Physiological markers of emotion and behavior dysregulation in externalizing psychopathology. Monogr Soc Res Child Dev. 2012;77(2):79-86.

48. Braet C, Theuwis L, van Durme K, Vandewalle J, Vandevivere E, Wante L, et al. Emotion regulation in children with emotional problems. Cogn Ther Res. 2014;38(5):493-504. doi:10.1007/s10608014-9616-X.

49. Fairholme CP, Nosen EL, Nillni YI, Schumacher JA, Tull MT, Coffey SF. Sleep disturbance and emotion dysregulation as transdiagnostic processes in a comorbid sample. Behav Res Ther. 2013;51(9):540-6. doi:10.1016/j.brat.2013.05.014.

50. Gil-Rivas V, McWhorter L. Self-medication. In: Miller PM et al., editors. Comprehensive addictive behaviors and disorders, volume 1: principles of addiction. San Diego: Elsevier Academic Press; 2013. p. 235-41. This review highlights the neurobiology of substance use disorders and self-medication, as well as describing similar underlying neurobiology and abnormalities in the stress response system that underlie the development of addiction and comorbid conditions.

51.• Goschke T. Dysfunctions of decision-making and cognitive control as transdiagnostic mechanisms of mental disorders: advances, gaps, and needs in current research. Int J Methods Psychiatr Res. 2014;23:41-57. doi:10.1002/mpr.1410. This paper highlights poor decision making and deficits in self-control and emotional control as core transdiagnostic factors that underlie many forms of psychopathology. The authors highlight the importance of focusing on the neurological mechanisms that underlie these associations.

52. Holtmann M, Buchmann AF, Esser G, Schmidt MH, Banaschewski T, Laucht M. The child behavior checklist-dysregulation profile predicts substance use, suicidality, and functional impairment: a 
longitudinal analysis. J Child Psychol Psychiatry. 2011;52(2):13947. doi:10.1111/j.1469-7610.2010.02309.x.

53.• Kober H. Emotion regulation in substance use disorders. In: Gross J, editor. Handbook of emotion regulation. 2nd ed. New York: Guilford Press; 2014. p. 428-46. This chapter reviews the importance of emotion regulation in the development of addiction and highlights the neurobiological underpinnings for this association. The model presented focuses primarily on the dysregulation associated with the experience of craving and the subsequent failure of the regulatory system to down-regulate the negative emotional experience associated with craving, leading to increased risk for substance use.

54. Moadab I, Gilbert T, Dishion T, Tucker DM. Frontolimbic activity in a frustrating task: covariation between patterns of coping and individual differences in externalizing and internalizing symptoms. Dev Psychopathol. 2010;22(2):391-404. doi:10.1017/ S0954579410000131.

55. Sobanski E, Banaschewski T, Asherson P, Buitelaar J, Chen W, Franke B, et al. Emotional lability in children and adolescents with attention deficit hyperactivity disorder (ADHD): clinical correlates and familial prevalence. J Child Psychol Psychiatry. 2010;51(8): 915-23. doi:10.1111/j.1469-7610.2010.02217.x.

56. Vine V, Aldao A. Impaired emotional clarity and psychopathology: a transdiagnostic deficit with symptom-specific pathways through emotion regulation. J Soc Clin Psychol. 2014;33(4):319-42. doi: 10.1521/jscp.2014.33.4.319.

57. Casey BJ, Ruberry EJ, Libby V, Glatt CE, Hare T, Soliman F, et al. Transitional and translational studies of risk for anxiety. Depression Anxiety. 2011;28(1):18-28. doi:10.1002/da.20783.

58. Van Ryzin MJ, Dishion TJ. Adolescent deviant peer clustering as an amplifying mechanism underlying the progression from early substance use to late adolescent dependence. J Child Psychol Psychiatry. 2014;55(10):1153-61. doi:10.1111/jcpp.12211.

59. Copeland WE, Adair CE, Smetanin P, Stiff D, Briante C, Colman I, et al. Diagnostic transitions from childhood to adolescence to early adulthood. J Child Psychol Psychiatry. 2013;54(7):791-9. doi:10. $1111 /$ jcpp. 12062.

60. Eisenberg N, Spinrad TL, Eggum ND. Emotion-related self-regulation and its relation to children's maladjustment. Annu Rev Clin Psychol. 2010;6:495-525. doi:10.1146/annurev.clinpsy.121208. 131208.

61. Bradley B, DeFife JA, Guarnaccia C, Phifer J, Fani N, Ressler KJ, et al. Emotion dysregulation and negative affect: association with psychiatric symptoms. J Clin Psychiatry. 2011;72(5):685-91. doi: 10.4088/JCP.10m06409blu.

62. Cheetham A, Allen NB, Whittle S, Simmons J, Yücel M, Lubman DI. Volumetric differences in the anterior cingulate cortex prospectively predict alcohol-related problems in adolescence. Psychopharmacology. 2014;231(8):1731-42. doi:10.1007/s00213014-3483-8

63. Hsu DT, Kirouac GJ, Zubieta J, Bhatnagar S (2014). Contributions of the paraventricular thalamic nucleus in the regulation of stress, motivation, and mood. Front Behav Neurosci. 8, doi:10.3389 fnbeh.2014.00073.

64. Cheetham A, Allen NB, Schwartz O, Simmons JG, Whittle S, Byrne ML, et al. Affective behavior and temperament predict the onset of smoking in adolescence. Psychol Addict Behav. 2015;29(2):347-54. doi:10.1037/adb0000048.

65. Cheetham A, Allen NB, Yücel M, Lubman DI. The role of affective dysregulation in drug addiction. Clin Psychol Rev. 2010;30(6): 621-34. doi:10.1016/j.cpr.2010.04.005.

66. Griffin KW, Lowe SR, Acevedo BP, Botvin GJ. Affective selfregulation trajectories during secondary school predict substance use among urban minority young adults. J Child Adolesc Subst Abus. 2015;24(4):228-34. doi:10.1080/1067828X.2013.812530.
67. Reynolds EK, Collado-Rodriguez A, MacPherson L, Lejuez C. Impulsivity, disinhibition, and risk taking in addiction. In: Miller PM, Ball SA, Bates ME, Blume AW, Kampman KM, Kavanagh DJ, et al., editors. Comprehensive addictive behaviors and disorders, volume 1: principles of addiction. San Diego: Elsevier Academic Press; 2013. p. 203-12.

68. Veilleux JC, Skinner KD, Reese ED, Shaver JA. Negative affect intensity influences drinking to cope through facets of emotion dysregulation. Personal Individ Differ. 2014;59:96-101. doi:10. 1016/j.paid.2013.11.012

69. Wilens TE, Martelon M, Anderson JP, Shelley-Abrahamson R, Biederman J. Difficulties in emotional regulation and substance use disorders: a controlled family study of bipolar adolescents. Drug Alcohol Depend. 2013;132(1-2):114-21. doi:10.1016/j. drugalcdep.2013.01.015.

70. Albein-Urios N, Verdejo-Román J, Asensio S, Soriano-Mas C, Martínez-González JM, Verdejo-García A. Re-appraisal of negative emotions in cocaine dependence: dysfunctional corticolimbic activation and connectivity. Addict Biol. 2014;19(3):415-26. doi:10. 1111/j.1369-1600.2012.00497.x.

71. Litt LC, Hien DA, Levin D. Adult antisocial behavior and affect regulation among primary crack/cocaine-using women. Psychol Women Q. 2003;27(2):143-52. doi:10.1111/1471-6402.00094.

72. Hopwood CJ, Schade N, Matusiewicz A, Daughters SB, Lejuez $\mathrm{CW}$. Emotion regulation promotes persistence in a residential substance abuse treatment. Subst Use Misuse. 2015;50(2):251-6. doi: 10.3109/10826084.2014.977393.

73. Cook BJ, Wonderlich SA, Lavender JM. The role of negative affect in eating disorders and substance use disorders. In: Brewerton TD, Dennis AB, editors. Eating disorders, addictions, and substance use disorders: research, clinical, and treatment perspectives. New York: Springer-Verlag Publishing; 2014. p. 363-78.

74. MacPherson L, Calvin NT, Richards JM, Guller L, Mayes LC, Crowley MJ, et al. Development and preliminary validation of a behavioral task of negative reinforcement underlying risk-taking and its relation to problem alcohol use in college freshmen. Alcohol Clin Exp Res. 2012;36(6):950-7. doi:10.1111/j.15300277.2011.01703.x.

75. MacPherson L, Reynolds EK, Daughters SB, Wang F, Cassidy J, Mayes LC, et al. Positive and negative reinforcement underlying risk behavior in early adolescents. Prev Sci. 2010;11(3):331-42. doi:10.1007/s11121-010-0172-7.

76. Shadur J, Hussong AM. Friendship intimacy, close friend drug use, and self-medication in adolescence. J Soc Pers Relat. 2014;31(8): 997-1018. doi:10.1177/0265407513516889.

77. Shomaker LB, Reina SA. Intraindividual variability in mood experience and mood regulation in childhood and adolescence. In: Diehl M, Hooker K, Sliwinski MJ, editors. Handbook of intraindividual variability across the life span. New York: Routledge/Taylor \& Francis Group; 2015. p. 103-22. This chapter highlights extant research on child and adolescent experiences of mood and emotion regulation and describes processes by which intraindividual variability in mood and regulation relate to risk for substance use and psychopathology.

78. Smith RC, Feldner MT, Badour CL. Substance use to regulate affective experiences in posttraumatic stress disorder: a review of laboratory-based studies. J Exp Psychopathol. 2011;2(1):3-27. doi:10.5127/jep.011310.

79. MacPherson L, Magidson JF, Reynolds EK, Kahler CW, Lejuez $\mathrm{CW}$. Changes in sensation seeking and risk-taking propensity predict increases in alcohol use among early adolescents. Alcohol Clin Exp Res. 2010;34(8):1400-8. doi:10.1111/j.1530-0277.2010. 01223.x.

80. Iacono WG, Malone SM, McGue M. Behavioral disinhibition and the development of early-onset addiction: common and specific 
influences. Annu Rev Clin Psychol. 2008;4:325-48. doi:10.1146/ annurev.clinpsy.4.022007.141157.

81. Zucker RA, Heitzeg MM, Nigg JT. Parsing the undercontrol-disinhibition pathway to substance use disorders: a multilevel developmental problem. Child Dev Perspect. 2011;5(4):248-55.

82. Hussong AM, Jones DJ, Stein GL, Baucom DH, Boeding S. An internalizing pathway to alcohol use and disorder. Psychol Addict Behav. 2011;25(3):390-404. doi:10.1037/a0024519.

83.• Hussong AM, Shadur J, Burns A, Stein G, Jones D, Solis J, et al. An early emerging internalizing pathway to substance use and disorder. In: Brown S, Zucker RA, editors. The oxford handbook of adolescent substance abuse. New York: Oxford University Press; 2015 (in press). A recent chapter highlighting the internalizing pathway to substance use disorders, with a focus on emotion regulation deficits as the core underlying risk across development. Mechanisms of risk for progression along the pathway are described. This chapter also highlights how particularly elevated risk for progression along the internalizing pathway may emerge for children of substance-dependent parents.

84. Matthys W, Vanderschuren LJMJ, Schutter DJLG. The neurobiology of oppositional defiant disorder and conduct disorder: altered functioning in three mental domains. Dev Psychopathol. 2013;25(1):193-207. doi:10.1017/S0954579412000272.

85. Hill SY, Tessner K, Wang S, Carter H, McDermott M. Temperament at 5 years of age predicts amygdala and orbitofrontal volume in the right hemisphere in adolescence. Psychiatry Res Neuroimaging. 2010;182(1):14-21. doi:10.1016/j.pscychresns. 2009.11.006.

86. Séguin J, Pilon M. Conduct and oppositional defiant disorders. In: Reddy LA, Weissman AS, Hale JB, editors. Neuropsychological assessment and intervention for youth: an evidence-based approach to emotional and behavioral disorders. Washington, DC: American Psychological Association; 2013. p. 177-200. doi:10.1037/14091008.

87. Crowley TJ, Dalwani MS, Mikulich-Gilbertson S, Du YP, Lejuez $\mathrm{CW}$, Raymond KM, et al. Risky decisions and their consequences: neural processing by boys with antisocial substance disorder. PLoS ONE. 2010;5(9), e12835. doi:10.1371/journal.pone.0012835.

88. Henderson HA, Pine DS, Fox NA. Behavioral inhibition and developmental risk: a dual-processing perspective. Neuropsychopharmacology. 2015;40(1):207-24. doi:10.1038/npp. 2014.189.
89. Williams LR, Fox NA, Lejuez CW, Reynolds EK, Henderson HA, Perez-Edgar K, et al. Early temperament, propensity for risk-taking and adolescent substance-related problems: a prospective multimethod investigation. Addict Behav. 2010;35(12):1148-51. doi: 10.1016/j.addbeh.2010.07.005.

90. Fox NA, Pine DS. Temperament and the emergence of anxiety disorders. J Am Acad Child Adolesc Psychiatry. 2012;51(2):1258. doi:10.1016/j.jaac.2011.10.006.

91. Penela EC, Walker OL, Degnan KA, Fox NA, Henderson HA. Early behavioral inhibition and emotion regulation: pathways toward social competence in middle childhood. Child Dev. 2015;86(4):1227-40. doi:10.1111/cdev.12384.

92. Kagan J. Behavioral inhibition as a risk factor for psychopathology. In: Beauchaine TP, Hinshaw SP, editors. Child and adolescent psychopathology. Hoboken: Wiley; 2008. p. 157-79.

93. Pittenger C, Etkin A (2008). Are there biological commonalities among different psychiatric disorders? In A. Tasman, J. Kay, J. Lieberman, M. First, \& M. Maj, (Eds.), Psychiatry (Third Edition), (pp. 243-256). John Wiley \& Sons, Ltd.

94. Miguel-Hidalgo J. Brain structural and functional changes in adolescents with psychiatric disorders. Int J Adolesc Med Health. 2013;25(3):245-56. doi:10.1515/ijamh-2013-0058.

95. Campbell-Sills L, Ellard KK, Barlow DH. Emotion regulation in anxiety disorders. In: Gross J, editor. Handbook of emotion regulation. 2nd ed. New York: The Guilford Press; 2014. p. 393-412.

96. Tull MT, McDermott MJ, Gratz KL, Coffey SF, Lejuez CW. Cocaine-related attentional bias following trauma cue exposure among cocaine dependent in-patients with and without posttraumatic stress disorder. Addiction. 2011;106(10):1810-8. doi: 10.1111/j.1360-0443.2011.03508.x.

97. Beauchaine TP, Neuhaus E, Zalewski M, Crowell SE, Potapova N. The effects of allostatic load on neural systems subserving motivation, mood regulation, and social affiliation. Dev Psychopathol. 2011;23(4):975-99. doi:10.1017/S0954579411000459.

98. Cairns RB, Elder GHJ, Costello EJ. Developmental science. New York: Cambridge University Press; 1996. doi:10.1017/ CBO9780511571114.

99. Cummings ME, Valentino K. Developmental psychopathology. In: Overton WF, Molenaar PCM, Lerner RM, editors. Handbook of child psychology and developmental science, volume 1: theory and method. 7th ed. Hoboken: Wiley; 2015. p. 566-606. 